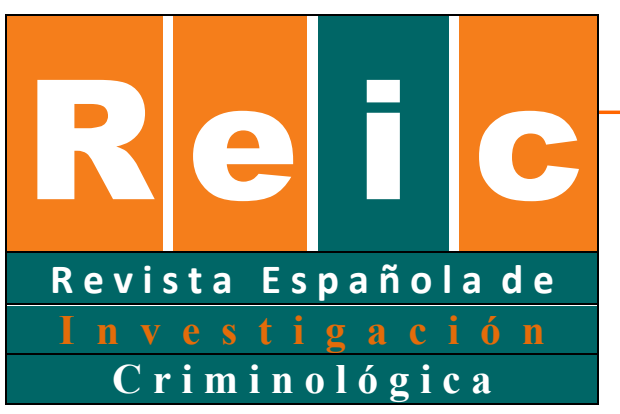

Salafranca \& Maldonado

\title{
Perfil geográfico de incendiarios urbanos
}

\section{Geographic profiling of urban arsonists}

\author{
Daniel Salafranca Barreda (D) y Diego J. Maldonado (D) \\ Guzmán ${ }^{1}$ Universidad Miguel Hernández de Elche \\ Universidad de Cádiz
}

\begin{abstract}
RESUMEN
No tenemos constancia de la existencia en este país de estudios sobre perfil geográfico de sujetos con un comportamiento incendiario en la vía pública, ni tampoco sobre investigaciones que hayan comprobado la eficacia de las estrategias del geoperfil para identificar, con cierta precisión, el área donde es más probable que resida el responsable de los incendios urbanos. En este estudio se propone, formula y comprueba una calibración en el parámetro $B$ (zona de seguridad) de la ecuación CGT propuesta por Rossmo (1995) para identificar el domicilio del incendiario, según sea éste de tipo serial, en masa o espontáneo. Para ello se analizan tres casos de incendiarios: en Santander en 2011, en Palma de Mallorca en 2016 y en Elche en 2017. El ajuste que se propone para el parámetro $B$ reduce tanto la distancia de error como los costes de búsqueda en los tres casos estudiados.
\end{abstract}

Palabras clave: perfil geográfico, incendiarios urbanos, zona de seguridad, punto de anclaje.

\begin{abstract}
Studies on the geographical profile of subjects with incendiary behavior on public roads have not been developed in our country, nor has the effectiveness of geoprofile strategies been proven to identify, with a certain precision, the area where it is most likely to reside the responsible for urban fires. In this study, a calibration is proposed, formulated and checked in the B value (buffer zone) of the CGT equation proposed by Rossmo (1995) to identify the residence of the arsonist, depending on whether they are serial, mass or spree. For this, three
\end{abstract}

${ }^{1}$ La correspondencia debe dirigirse a: Daniel Salafranca Barreda. d.salafranca@crimina.es

Revista Española de Investigación Criminológica

Artículo 13, Número 16 (2018)

https://doi.org/10.46381/reic.v16i0.197

www.criminologia.net

ISSN: 1696-9219 
cases of arsonists are analyzed: one in Santander in 2011, another in Palma de Mallorca in 2016 and another in Elche in 2017. The proposed adjustment for parameter B reduces both the distance of error as search costs in the three cases studied.

Keywords: geographic profiling, urban arsonists, buffer zone, anchor point.

\section{Introducción}

Ancestralmente el ser humano ha manifestado una intensa fascinación por el fuego. Una vez que descubre el poder de este fenómeno y la capacidad de controlarlo, con objeto de satisfacer alguna necesidad individual, surge una nueva categoría criminal: el incendio intencionado (Davis \& Lauber, 1999). Dicho acto puede responder a motivaciones de todo tipo. Al mismo tiempo, puede afectar a multitud de objetos, edificios, personas o al medio ambiente, y su distribución en el espacio y el tiempo no es aleatoria (Felson \& Clarke, 1998). En España, a diferencia de los estudios sobre incendios forestales, las investigaciones sobre los fuegos que se declaran en la vía pública carecen de la atención que precisan estos actos. Muestra de ello es que los trabajos científicos sobre posibles perfiles criminales de incendiarios se limitan exclusivamente a los de tipo forestal, sin que exista un perfil criminal del incendiario en entornos urbanos de nuestro país. Así, un trabajo declaró que "los incendios de este estudio no han tenido efectos sobre entornos "urbanos", pero sí, naturalmente, sobre entornos “rurales”, principalmente los forestales..." (El Mundo, 2010, p.20). No obstante, la gravedad de los fuegos que afectan a bosques y otros espacios naturales no debe restar importancia a los incendios urbanos. Así, los problemas de seguridad pública aumentan a medida que crecen las ciudades, convirtiéndose en un problema social que afecta a la calidad de vida de la población (Bogomolov et al., 2014).

La hemeroteca es la única fuente de la cual pueden extraerse datos sobre incendios urbanos, si bien es cierto que no describe, porque no es su labor ni están en condiciones de hacerlo, las verdaderas causas que obran tras esos incendios. No obstante, la prensa y los comunicados oficiales de los distintos gobiernos locales sí nos permiten hacernos una idea de los costes derivados de los incendios provocados en la vía pública. Por ejemplo, el

\section{Revista Española de Investigación Criminológica}


Ayuntamiento de Zaragoza estimó que los daños sufridos por quema de contenedores en 2014 fueron superiores a los 174.000 euros (Fernández, 2014). Además, el riesgo para la vida de los vecinos es también evidente. En 2011 un sujeto actuó en Santander prendiendo fuego a ocho portales de vecinos. Afortunadamente no se causaron víctimas a pesar de la evidente situación de riesgo generada (Europapress, 2011). Aun así, y como se ha adelantado, no se hallaron investigaciones sobre incendiarios urbanos en nuestro país, y más aún si se aborda la problemática desde un punto de vista del perfil geográfico. Tampoco se han localizado trabajos recientes en los que se aplique el geoperfil para capturar a incendiarios que actuaran en la vía pública. Algunos trabajos (Kocsis \& Irwin, 1997; Tamura \& Suzuki, 1997) hacen referencia a la idoneidad de la hipótesis del círculo de Canter para capturar a incendiarios entre otros delincuentes, pero no se hallaron investigaciones más recientes que hayan empleado el geoperfil exclusivamente para detener al incendiario. En general la tendencia de los estudios para todos los delincuentes seriales, incluidos los incendiarios, ha sido el análisis del viaje al crimen en términos de distancia recorrida por el criminal desde su domicilio hasta el lugar del delito (Curman, 2004; Hewitt \& Beauregard, 2017; Lundrigan \& Czarnomski, 2006; Warren et al, 1998), pero en nuestro país los estudios de viaje al crimen con incendiarios tampoco se hallaron.

La ausencia de investigaciones obliga a acudir a trabajos de expertos extranjeros, donde sí pueden encontrarse estudios sobre modelos de comportamiento espacial basados en los aspectos motivacionales del incendio. En este sentido, advierte Kielasinska (2011) que las clasificaciones sobre las distintas motivaciones que pueden existir detrás de esos actos varían notablemente en la literatura, siendo aquí donde se concentran las mayores dificultades. Sin embargo, los estudios sobre la eficacia del perfil geográfico para determinar la residencia del incendiario tampoco parecen muy abundantes.

Por todo esto, el presente artículo profundiza en cómo medir el componente espacial del perfil geográfico del incendiario en entornos urbanos y su utilidad en el marco de una investigación policial, realizando un ajuste matemático para que las áreas señaladas por el perfil sean más precisas de cara a identificar dónde habita el incendiario aun desconocido. Para ello se propone, formula y comprueba una calibración en el parámetro $B$ (zona de

\section{Revista Española de Investigación Criminológica}

Artículo 13, Número 16 (2018)

https://doi.org/10.46381/reic.v16i0.197

www.criminologia.net

ISSN: 1696-9219 
seguridad) de la ecuación denominada CGT (por sus silgas en inglés Criminal GeographicTargeting) propuesta por Rossmo (1995) para identificar el punto de anclaje del incendiario, según sea éste de tipo serial, en masa o espontáneo. Merece la pena destacar que Canter yYoungs (2008) afirman que el algoritmo CGT se ha usado en investigaciones policiales e incluso se ha testado en la resolución de casos sobre asesinos, violadores e incendiarios en serie, aunque, de nuevo, los ejemplos que desarrollan los autores se refieren solo a los dos primeros casos. La fórmula CGT de Rossmo (1995) incorpora dos ideas importantes:

1. Los delincuentes no viajarán demasiado lejos para cometer sus crímenes. Esto se conoce como decaimiento con la distancia, que se ejemplificará con una gráfica más adelante.

2. Hay un área alrededor de la residencia del delincuente (zona de seguridad) donde es menos probable que éste cometa sus crímenes, puesto que los objetivos son vistos como menos deseables debido al riesgo percibido asociado con operar demasiado cerca del punto de anclaje ${ }^{2}$.

Por lo tanto, el valor $B$ (zona de seguridad) se vuelve excepcionalmente importante y necesita su propia heurística para garantizar su precisión en los incendiarios urbanos. En la ecuación CGT de Rossmo, la zona de seguridad es expresada por el valor $B$ (zona de seguridad), que equivale a la mitad de la media del vecino más cercano. El cálculo para la distancia promedio del vecino más cercano puede verse en la Figura 1.

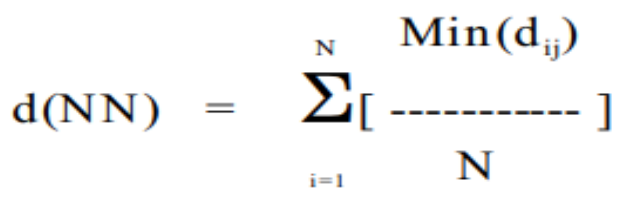

Figura 1: Promedio del vecino más cercano

\footnotetext{
${ }^{2}$ Para saber más véase Zouh, Lian y Chen, (2012, pp.114).Dicha zona es un concepto desarrollado por Brantingham \& Brantingham (1981) y señala la disminución de la actividad criminal cerca del punto de anclaje del delincuente.
}

Revista Española de Investigación Criminológica

Artículo 13, Número 16 (2018)

https://doi.org/10.46381/reic.v16i0.197

www.criminologia.net

ISSN: $1696-9219$ 
Min (dij) es la distancia entre cada punto y su área restante y $\mathrm{N}$ es el número de puntos en la distribución. Por lo tanto, se calcula la distancia desde un punto único a cualquier otro punto y se selecciona la menor distancia. Luego, se toma el siguiente punto y se calcula la distancia a todos los otros puntos (incluido el primer punto medido) con el más cercano seleccionado y a la primera distancia mínima. Este proceso se repite hasta que todos los puntos hayan sido seleccionados por su vecino más cercano. La suma total de las distancias mínimas se divide por $\mathrm{N}$, el tamaño de la muestra, para producir un promedio mínimo de diferencia. Así, Rossmo divide entre dos el resultado del vecino más cercano, y el valor resultante de tal división será el que incluya en el parámetro $B$ de la fórmula CGT.
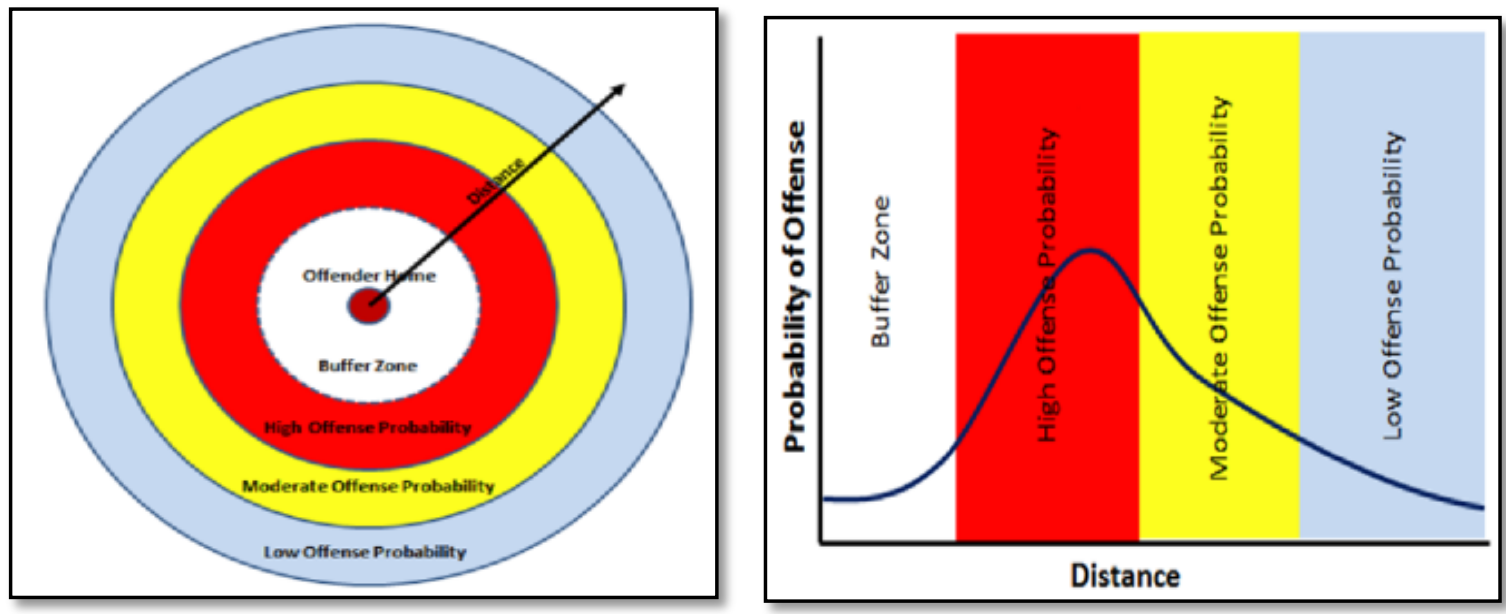

Figura 2: Zona de seguridad (Bruce \&

Smith, 2011) 


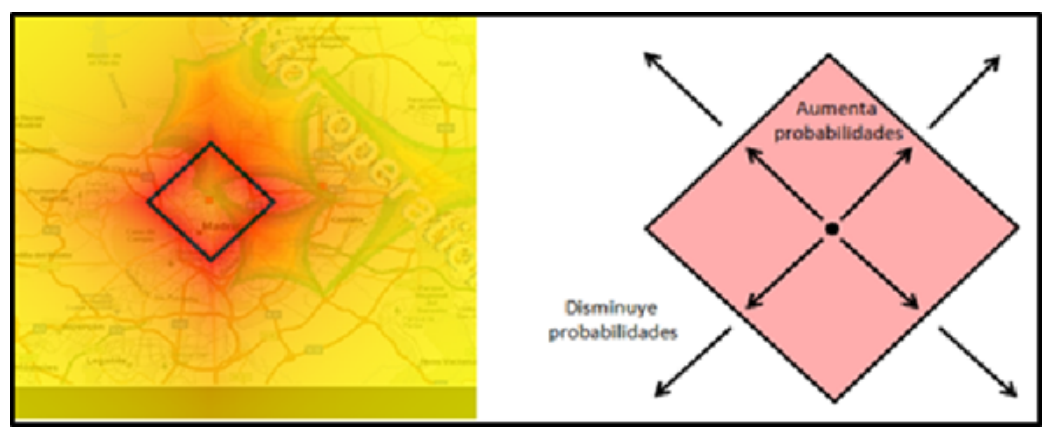

Figura 3: Zona de Seguridad según Rossmo. Elaboración propia

El modelo propuesto a través del ajuste se ha denominado PIRO (Punto Incendiario Rossmo). Y ¿por qué es necesario realizar un ajuste en esta fórmula? Las funciones matemáticas no pueden usarse indistintamente de la geografía, del diseño urbano y, mucho menos, de la tipología delictiva. En la mayoría de los casos analizados para confeccionar la muestra de este estudio los incendiarios no inician un fuego, regresan a su domicilio o punto de anclaje, experimentan un periodo de enfriamiento, salen de casa, vuelven a iniciar otro fuego y regresan de nuevo a su hogar. Al contrario, muchos de estos incendiarios cometen una oleada de incendios en el mismo día o intercalan esta oleada con periodos de enfriamiento que pueden ser de días o semanas. Por esta razón las funciones de probabilidad no señalan con precisión el domicilio del delincuente, de forma que la distancia de error, es decir, la distancia entre el domicilio real del incendiario y del punto de mayor probabilidad sugerido por el geoperfil (Rich \& Shively, 2005), dificulta la identificación del área donde realmente habita el responsable de los fuegos.

\subsection{Pirómanos o incendiarios. La importancia de la terminología}

Los términos pirómano e incendiario se han empleado como sinónimos el uno del otro, lo que ha provocado ciertas limitaciones y confusiones pedagógicas y metodológicas. Los medios de comunicación son un claro ejemplo de ello, y es posible comprobarlo en el trabajo realizado por Aniceto (2008), donde se muestra cómo la prensa narraba y titulaba distintos casos de incendios forestales acaecidos en España. El resultado del análisis llevado a cabo

\section{Revista Española de Investigación Criminológica}


por el autor muestra una tendencia a afirmar con rotundidad que el responsable es un pirómano, cuando ni siquiera se ha podido afirmar la existencia de una patología que reúna todos los criterios establecidos para la piromanía.

Basta con acudir al diccionario de la Real Academia de la Lengua Española (RAE) para apreciar que ambos términos no vienen a decir lo mismo. Así, el pirómano se define como “dicho de una persona: que padece piromanía”, siendo la piromanía definida como la “tendencia patológica a la provocación de incendios”. Una definición idéntica de este término puede leerse en el diccionario básico de criminalística (Álvarez, 2004). Se observa cómo se hace mención a la existencia de una patología para delimitar el significado de piromanía. Por su parte, la RAE define al incendiario como "aquel que incendia con premeditación, con afán de lucro o por maldad”. No se alude a una patología como base del comportamiento incendiario, siendo el móvil otro distinto, como puede ser la venganza, la búsqueda de beneficios, etc.

Puede entenderse aún más esta diferencia si se observan los siguientes datos: entre 2001 y 2014, de los 3.692 incendios forestales intencionados en Andalucía, solo 174 (4.71\%) fueron cometidos por pirómanos. Igualmente, en Galicia, para el mismo periodo de tiempo, de los 66.630 incendios forestales intencionados, 5.597 (8.40\%) fueron cometidos por pirómanos. Los datos presentados pueden consultarse en la web del Ministerio de Agricultura y Pesca, Alimentación y Medioambiente, donde se hace una distinción expresa entre ambas categorías.

¿Cuándo podemos decir, entonces, que el responsable de los incendios es un pirómano? El Manual Diagnóstico y Estadístico de Trastornos Mentales (DSM-V) sitúa la piromanía dentro de los trastornos destructivos, del control de impulsos y de la conducta, y la describe como un "patrón de comportamiento que lleva a provocar incendios por puro placer, gratificación o liberación de la tensión”3(American Psychiatric Association, 2014, p. 249).

\footnotetext{
${ }^{3}$ Aunque la última versión del DSM no especifique el número de criterios mínimos que ha de cumplir el sujeto para el diagnóstico de la piromanía, es sabido que no basta con cumplir solo uno de ellos. Aniceto (2017) lo explica con un ejemplo. "A finales de los 80 o principio de los 90 del pasado siglo varios incendios fueron provocados en zonas forestales cercanas al municipio de Ubrique (Cádiz). Los fuegos se atribuyeron al juego

Revista Española de Investigación Criminológica
}

Artículo 13, Número 16 (2018)

https://doi.org/10.46381/reic.v16i0.197

www.criminologia.net

ISSN: 1696-9219 
A los efectos de este estudio, y ante la falta de datos que nos permitan afirmar con rotundidad que los tres casos analizados cumplen los criterios de piromanía, emplearemos en todo momento el término incendiario, pues, de todo lo descrito hasta ahora, se está en condiciones de afirmar "que todos los pirómanos son incendiarios, pero muy pocos incendiarios cumplen los criterios para ser pirómanos” (Aniceto, 2017, p.3).

\subsection{Clasificación de los incendiarios: una problemática evidente}

Uno de los principales problemas en el abordaje de los incendiarios como objeto de análisis es la clasificación que se hace en cuanto a los mismos, ya no solo porque puedan establecerse varios criterios para su categorización, sino porque, incluso usando los mismos criterios, existen distintas tipologías según el autor o la institución que lleve a cabo la investigación.

Tras una revisión bibliográfica (Douglas, 2006; Fritzon, 2001; Kocsis \& Cooksey, 2002; Lauber, 1999) puede afirmarse que son dos los principales criterios a los que se acude para clasificar a los incendiarios: la motivación que ha llevado al sujeto a iniciar el fuego y el patrón de comportamiento que presenta. Dado que el geoperfil se emplea para señalar el área más probable donde tenga el incendiario, aun desconocido, su domicilio, la clasificación atendiendo a las motivaciones no resulta de nuestro interés, pues no conocemos aun al incendiario $\mathrm{y}$, por tanto, tampoco podemos saber qué motivos le ha llevado a actuar. No obstante, en aras de mostrar la controversia existente en cuanto a los sistemas clasificatorios de los sujetos incendiarios, se expone brevemente en las siguientes líneas algunos ejemplos de clasificación sugeridos.

Douglas et al. (2006) proponen en la segunda edición del manual clasificatorio del crimen seis tipologías de incendiarios en función de la motivación que obre tras los actos: (1) los incendiarios motivados por el vandalismo, (2) los incendiarios motivados por la emoción o excitación, (3) los incendiarios motivados por la venganza, (4) los que incendian para ocultar el delito, (5) aquellos que buscan beneficios y (6) aquellos que están motivados por

\footnotetext{
de niños que, fascinados por ver cómo operaba el helicóptero, prendieron fuego deliberado en varias ocasiones. La fascinación por contemplar las labores de extinción son evidentes, pero no nos permite diagnosticar una piromanía a los niños responsables del fuego" (p.4).
}

Revista Española de Investigación Criminológica

Artículo 13, Número 16 (2018)

https://doi.org/10.46381/reic.v16i0.197

www.criminologia.net

ISSN: 1696-9219 
el extremismo para iniciar el fuego; mientras que Fritzon (2001) divide a los incendiarios según cuatro procesos psicológicos subyacentes, determinados en función de si el objetivo del fuego es una persona o propiedad y de si la motivación del incendiario tiene carácter emocional o instrumental. Así, los cuatro procesos resultantes son: la desesperación (el objetivo es una persona y la motivación es emocional), la exhibición (el objetivo es un objeto o propiedad y la motivación es emocional), el daño (el objetivo es una propiedad pero la motivación es instrumental) y la destrucción (se dirige contra las personas y la motivación es de carácter instrumental). Por su parte, Aniceto (2017), propone una clasificación más concisa, según sea la motivación de índole emocional o instrumental, si bien es cierto que recoge la mayoría de las tipologías hasta ahora vistas (Tabla 1).

Tabla 1.

Clasificación de incendiarios

\begin{tabular}{|c|c|c|}
\hline Tipo & Descripción & Ejemplo \\
\hline Conflicto/Venganza & $\begin{array}{l}\text { Motivación emocional } \\
\text { desarrollada sobre la base de las } \\
\text { relaciones interpersonales. } \\
\text { Proyectada contra las personas, } \\
\text { colectivos, propiedades o } \\
\text { Administraciones Públicas }\end{array}$ & $\begin{array}{l}\text { "Me debes dinero y no me lo has } \\
\text { devuelto. Entonces te quemo el } \\
\text { coche". }\end{array}$ \\
\hline Vandalismo/Gamberrismo & $\begin{array}{l}\text { El fuego se usa para satisfacer el } \\
\text { deseo personal de llevar a cabo } \\
\text { una hazaña o proeza, como medio } \\
\text { de entretenimiento o para sentirse } \\
\text { integrado en el grupo. }\end{array}$ & $\begin{array}{llr}\text { "¿A que no eres capaz de } \\
\text { hacerlo?" "Verás qué risas } \\
\text { cuando } & \text { quememos } & \text { el } \\
\text { contenedor". } & & \end{array}$ \\
\hline Obtención del beneficio & $\begin{array}{l}\text { Motivación instrumental. El } \\
\text { fuego tiene como fin alcanzar un } \\
\text { determinado objetivo que me va a } \\
\text { producir un beneficio }\end{array}$ & $\begin{array}{l}\text { "Voy a quemar mi coche para } \\
\text { cobrar un seguro". "Robo un } \\
\text { coche que uso para cometer otro } \\
\text { delito y luego lo quemo para } \\
\text { eliminar mis huellas". }\end{array}$ \\
\hline Comportamiento desviado & $\begin{array}{l}\text { Motivación de índole emocional, } \\
\text { sin motivo o justificación } \\
\text { aparente, o bien generado por una } \\
\text { motivación rara, extraña o } \\
\text { extravagante. Aquí entra la } \\
\text { piromanía. }\end{array}$ & $\begin{array}{l}\text { "Siento una tensión que solo soy } \\
\text { capaz de aliviar con el fuego". }\end{array}$ \\
\hline
\end{tabular}

Falta entonces un criterio común a la hora de clasificar a los incendiarios, y así lo afirman también David yLauber (1999), que tras realizar una revisión de la literatura critican

\section{Revista Española de Investigación Criminológica}

Artículo 13, Número 16 (2018)

https://doi.org/10.46381/reic.v16i0.197

www.criminologia.net

ISSN: 1696-9219 
la falta de consistencia y cohesión en los intentos de proporcionar un esquema de clasificación adecuado.

Por otra parte, la clasificación que aquí resulta de interés de cara al objeto de nuestro estudio es aquella que se establece según el número de víctimas, la existencia o no de un periodo de enfriamiento, el número de eventos y el número de localizaciones en cada acto. Puede observarse entonces que dicha clasificación responde a los patrones de comportamiento expresados por los sujetos. Atendiendo a estos criterios, Douglas et al. (2006) hablan de tres tipos de incendiarios: el serial, el incendiario en masa y el incendiario espontáneo (Tabla 2).

\section{Tabla 2.}

Clasificación de incendiarios según número de víctimas, número de eventos, número de localizaciones y existencia o no de un periodo de enfriamiento emocional

\begin{tabular}{|l|l|l|l|}
\hline & En serie & En masa & Espontáneo \\
\hline $\begin{array}{l}\text { Número de víctimas } \\
\text { (persona/objeto/espacio) }\end{array}$ & 3 o más & 4 o más & 2 o más \\
\hline Número de eventos & 3 o más & 1 & 1 \\
\hline $\begin{array}{l}\text { Número de } \\
\text { localizaciones }\end{array}$ & 3 o más & 1 & 2 o más \\
\hline Periodo de enfriamiento & Sí & No & No \\
\hline
\end{tabular}

Un ejemplo de incendiario en serie es aquel sujeto que prende fuego a un contenedor, regresa a su casa, y vuelve a salir para iniciar otro fuego pasado uno o más días, semanas, meses o incluso años. Por su parte, el incendiario en masa es aquel que, por ejemplo, prende fuego a un edificio en el que arden las cuatro plantas. Un ejemplo de incendiario espontáneo sería aquel que recorre las calles en una misma noche prendiendo varios fuegos a vehículos, contenedores, etc.

\section{Revista Española de Investigación Criminológica}


Para la realización de este estudio se considerará de manera exclusiva la clasificación que acaba de presentarse, realizándose los ajustes en la función de probabilidad ${ }^{4}$ según sea el incendiario de un tipo $\mathrm{u}$ otro.

\subsection{El comportamiento espacial de los incendiarios}

El perfil geográfico es una técnica de investigación criminal que, mediante el análisis de la ubicación de los delitos que pertenecen a una serie, pretende determinar el área donde es más probable que el delincuente tenga su domicilio o base de operaciones (Rossmo\&Summers, 2015). Dicha técnica es capaz de reducir los costes en la investigación, pues señala aquellas áreas donde deberían destinarse los recursos para detener al delincuente responsable de una serie de hechos. Así, Van Daele (2010) afirma que la variable "lugar del delito" es seis veces más predictiva que la propia identidad del criminal, asegurando al mismo tiempo que la ubicación de los hechos delictivos ofrece una serie de oportunidades innegables al profesional de la criminología. A raíz de esta idea, se han desarrollado investigaciones en las que se ha establecido una relación entre la ubicación de las escenas del delito y un patrón de decaimiento con la distancia. Algunos autores como BartolyBartol (2012) y Van Daele (2010) describen el principio de decadencia con la distancia y lo aplican al perfil geográfico. De esta forma, el principio hipotetiza que a medida que la distancia respecto al domicilio del delincuente aumenta, la probabilidad de que cometa un delito disminuye, o lo que es lo mismo, la probabilidad disminuye cuanto mayor sea la distancia desde la base del delincuente (Figura 4).

\footnotetext{
${ }^{4}$ Funciones cuyo objetivo es definir la probabilidad de que el delincuente haya viajado una distancia determinada para cometer un delito. La distribución de la distancia recorrida variará según el tipo de delito, la hora del día, el método de operación y muchas otras variables (Levine \& associates, 2015).
}

Revista Española de Investigación Criminológica

Artículo 13, Número 16 (2018)

https://doi.org/10.46381/reic.v16i0.197

www.criminologia.net

ISSN: 1696-9219 


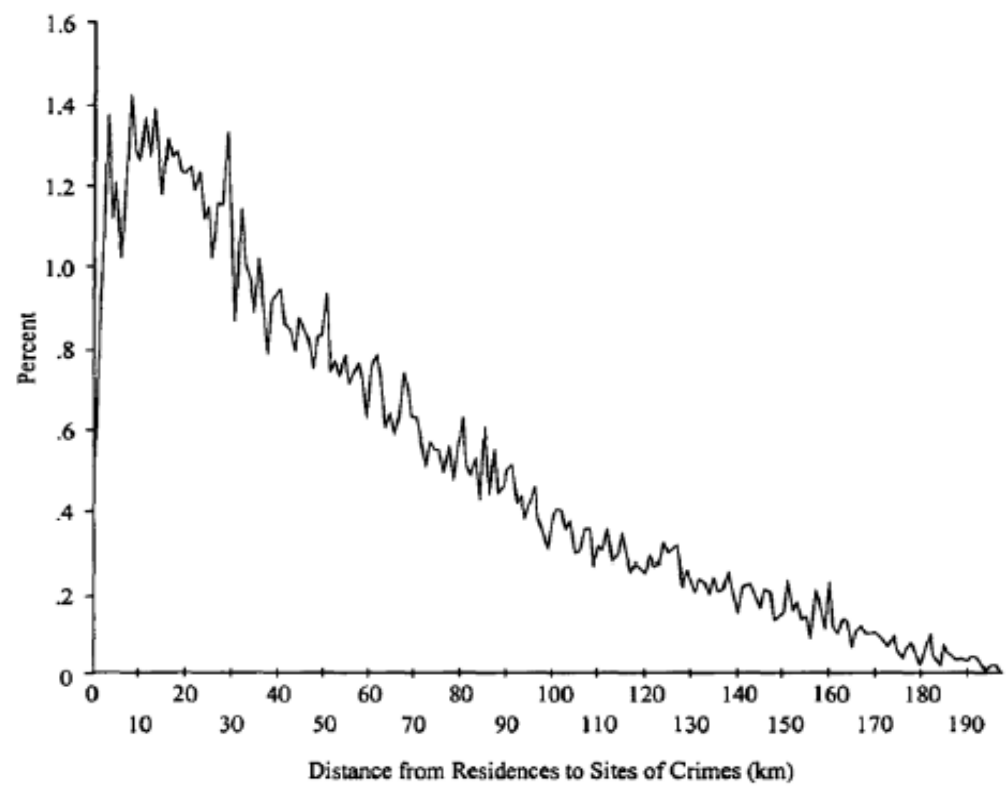

Figura 4: Ejemplo de curva de decaimiento con la distancia (Van Daele, 2005)

Pueden citarse estudios al respecto, como el realizado por White (1932), que encontró una distancia media de $2.7 \mathrm{~km}$ para todos los tipos de criminalidad y fue de los primeros en sugerir que cuando los delitos se dirigen contra las personas, el criminal delinque más cerca de casa (distancia media de $1.3 \mathrm{~km}$ ), mientras que en los delitos dirigidos contra la propiedad el delincuente viaja distancias más largas (una media de $2.8 \mathrm{~km}$ ). Willes y Costello (2000), encontraron que los criminales recorren una media de $3.1 \mathrm{~km}$ desde su punto de anclaje ${ }^{5}$ hasta el lugar del delito.

En el caso de las distancias recorridas por los incendiarios en el viaje al delito, la literatura es más escasa. Fritzon (2001), analiza las distancias recorridas por el incendiario según tres variables: (1) las motivaciones del sujeto según fueran éstas de carácter emocional o instrumental, (2) según la dimensión empíricamente observable y (3) según las características del propio sujeto (edad, historia familiar, historia psiquiátrica, delincuencia juvenil y repetición del incendio). Algunos de los resultados hallados mostraron que el

\footnotetext{
${ }^{5}$ El punto de anclaje se define como el punto más importante de la vida espacial. Normalmente es el domicilio, pero puede ser cualquier otro como el lugar de trabajo, el gimnasio, un bar, etc. (Zouh, Lian \& Chen, 2012, pp.114).
}

Revista Española de Investigación Criminológica

Artículo 13, Número 16 (2018)

https://doi.org/10.46381/reic.v16i0.197

www.criminologia.net

ISSN: 1696-9219 
incendiario exhibicionista no viajaba más de $2 \mathrm{~km}$ y los del tipo dañino recorrieron una media de $2.11 \mathrm{~km}$. Por último, el incendiario de tipo destructor recorrió un mínimo de $0.02 \mathrm{~km} \mathrm{y}$ un máximo de $116 \mathrm{~km}$. Se observa que los incendiarios con motivos emocionales viajan mucho menos que los instrumentales, estando estos últimos dispuestos a recorrer mayores distancias, dependiendo principalmente de la distribución de sus objetivos y de los beneficios que obtendrían por el delito ${ }^{6}$.

La hipótesis de que los incendiarios recorren distancias cortas es confirmada por Edwards (2004) en su análisis sobre los patrones de movimiento de los incendiarios en serie que han sido condenados, llegando a afirmar que estos sujetos se desplazan al lugar del delito a pie y viven dentro de 1.61 kilómetros de distancia respecto a la escena del crimen. La distancia promedio mínima que recorrían los incendiarios fue de $0.507 \mathrm{~km}$ según los hallazgos del autor, de forma que el $82 \%$ inició los incendios dentro de los $5 \mathrm{~km}$ respecto a su hogar. Afirma también el citado autor que cuanto mayor es la distancia entre el primer y último incendio, mayor será también la distancia entre el último fuego y el domicilio del incendiario.

Junto al anterior autor, Curman (2004) también sugiere la tendencia de los incendiarios para iniciar los fuegos cerca de casa. A pesar de que las distancias recorridas variaban según la zona de Vancouver, se halló una media de $2.1 \mathrm{~km}$ y una mediana de 1.3 $\mathrm{km}$ de distancia.

No obstante, las investigaciones que acaban de citarse llegan a los resultados presentados a partir de una muestra de incendiarios ya detenidos $\mathrm{y}$, por tanto, conocidos. Los hallazgos en las distancias recorridas por los sujetos con comportamiento incendiario se realizan a partir de variables como "distancia desde su hogar", “edad", "género", o “motivaciones". Sin embargo, los resultados descritos no podrían hallarse si no se identificara al criminal, pues solo sería posible conocer las distintas ubicaciones de los fuegos que inician en la vía pública, pero no quién los está cometiendo.

${ }^{6}$ La teoría de la elección racional hipotetiza que los criminales realizan un cálculo de los costes y beneficios derivados de cometer el delito. Desde un punto de vista del perfil geográfico, el delincuente estará dispuesto a recorrer mayores distancias cuando determina que los beneficios que espera obtener supera con creces los costes (en término de ser detenido).

Revista Española de Investigación Criminológica

Artículo 13, Número 16 (2018)

https://doi.org/10.46381/reic.v16i0.197

www.criminologia.net

ISSN: 1696-9219 
Esta cuestión es la que marca la diferencia con el presente estudio, pues se realizan ajustes en las funciones de probabilidad según se trate de un incendiario en serie, en masa o de tipo espontáneo, algo que se puede conocer realizando tan solo un análisis espaciotemporal de los incendios, sin necesidad de conocer la identidad del responsable. Claro está que para determinar el ajuste específico necesario para cada tipo de incendiario ha sido imprescindible analizar tres casos con sujetos ya detenidos, en aras de comprobar si el ajuste realizado señalaba de forma acertada el domicilio de aquel. Pero a pesar de esta cuestión metodológica, el resultado deviene en un ajuste de la fórmula empleada que puede usarse para acelerar la investigación y garantizar la pronta aprehensión del responsable de los incendios en el entorno urbano.

\section{Método}

En este punto se explica la metodología seguida para, por un lado, seleccionar los casos de incendiarios urbanos que forman parte de la muestra y, por otro, para crear un perfil geográfico a partir de un modelo que proponemos (modelo PIRO), haciendo referencia a la fórmula CGT de Rossmo (1995).

\subsection{Selección de casos y recolección de datos}

Para la selección de los casos se ha comprobado que éstos reunían los criterios descritos por Rossmo (2000), de manera que aquellos que cumplían tales requisitos eran de nuevo revisados en un segundo momento para consultar si se disponían de todos los datos necesarios para su geoperfilación.

Los criterios de Rossmo (2000) son los siguientes: primero, cada incendiario ha tenido que iniciar, por lo menos, cinco incendios. Como segundo criterio, se ha de partir de la presunción de que el incendiario dispone de un único y estable punto de anclaje, ya que, en caso contrario, el geoperfil no estará capacitado para predecir con precisión el domicilio del incendiario. Según el tercer criterio, el punto de anclaje ha de estar situado en el área de actuación del incendiario, ya que si su acción delictiva la lleva a cabo fuera de dicha área los programas informáticos serán incapaces de manejar e interpretar adecuadamente las variables

Revista Española de Investigación Criminológica

Artículo 13, Número 16 (2018)

https://doi.org/10.46381/reic.v16i0.197

www.criminologia.net

ISSN: 1696-9219 
contempladas (Van der Kemp \& Van der Koppen, 2008). Por último, se requiere que el tipo de objetivo pretendido por el criminal sea relativamente uniforme.

Cuando se seleccionan los casos que cumplen los requisitos arriba expuestos se procede a la recolección de los datos que son necesarios para poder ubicar los incendios en el mapa y realizar los análisis del geoperfil. Estos datos son: número de incendios provocados por el incendiario, localización específica de cada uno de los fuegos iniciados y la ubicación del domicilio del incendiario. Para la obtención de dichos datos se ha consultado la hemeroteca. Los datos aparecidos en prensa se han aprovechado para establecer contacto con los locales supuestamente afectados por el incendio ${ }^{7}$, con objeto de conocer la ubicación exacta del incendio. También se ha contactado con el servicio de bomberos de algunas localidades ${ }^{8}$.

En relación con el domicilio de los incendiarios y con el fin de proteger los datos personales, se ha introducido una modificación aleatoria del punto visualizado en la leyenda de los mapas con respecto a la ubicación de su domicilio.

De los siete casos propuestos para conformar la muestra solo pudieron extraerse todos los datos necesarios de tres de ellos ${ }^{9}$. El resultado de la selección y recolección de datos deviene en una muestra compuesta por tres casos que se usan para el análisis de incendiarios urbanos: uno en Elche durante 2017, otro en Palma de Mallorca en 2016 y un último incendiario que actuó en Santander en 2011.

Atendiendo a la clasificación de incendiarios según Douglas et al. (2006) que se expuso anteriormente (ver Tabla 2), el incendiario de Santander pertenece a la categoría "en serie". Los otros dos casos presentan una tipología mixta, puesto que entre cada oleada de incendios existe un periodo de enfriamiento emocional, siendo este enfriamiento exclusivo de los incendiarios en serie. Sin embargo, para perfilar geográficamente el caso según la

\footnotetext{
${ }^{7}$ Una vez se disponía de una localización aproximada del incendio se contactaba por teléfono con algún local aleatorio sito en la zona afectaba, con objeto de preguntar por la localización concreta del fuego. Todas las llamadas que se realizaron resultaron ser fructuosas.

${ }^{8}$ Se estableció contacto telefónico con el servicio de bomberos de Santander y Palma de Mallorca.

${ }^{9}$ De los casos restantes no pudo extraerse la información completa por varios motivos: el caso estaba siendo objeto de un proceso penal, el responsable cumplía una medida en centro psiquiátrico y sus datos estaban protegidos, los Servicios de Extinción de Incendios solicitaban el pago de una tasa para valorar la emisión o no de los datos requeridos y algunos periódicos no disponían de dichos datos al completo.
}

Revista Española de Investigación Criminológica

Artículo 13, Número 16 (2018)

https://doi.org/10.46381/reic.v16i0.197

www.criminologia.net

ISSN: 1696-9219 
metodología elegida para este trabajo, el incendiario ha de encuadrarse sólo en una de las categorías. Entonces, debido a los periodos de enfriamiento descritos en los incendiarios de Palma y Elche, se ha considerado que aquellos pertenecen también a la categoría serial. Como consecuencia, los tres incendiarios estudiados son de tipo serial, y por tanto los ajustes en la fórmula se realizarán conforme a dicha tipología.

\subsection{Estrategia para el perfilado geográfico}

Los Sistemas de Información Geográfica (SIG) son una herramienta idónea, ya que permiten utilizar información variada y de distintas fuentes que facilita el análisis simultáneo de un mismo problema (Jiménez, 2013). En base a lo que acaba de argumentarse, se han utilizado para este estudio los siguientes programas informáticos: ArcGis ${ }^{10}$ 10.3.1, GvSIG 2.3 ${ }^{11}$, CrimeStat IV $^{12}$ y Yaahp ${ }^{13}$.

Para esta investigación se ha seguido la línea de trabajo de Snook, Zito, Bennelly Taylor (2005) en la que clasifican los algoritmos matemáticos para el perfil geográfico en dos categorías básicas: estrategias de distribución espacial y estrategias de distancia de probabilidad, siendo esta última en la que nos centraremos fundamentalmente.

Las estrategias de distancia de probabilidad desarrollan una metodología para situar el punto de anclaje del delincuente en relación con la ubicación de los delitos cometidos, definiendo su área de actuación la zona que contiene la residencia del criminal. Los modelos más populares dentro de estas estrategias incluyen el modelo CGT de Rossmo (Roosmo 1995), el método de Canter y el método de Levine (ver Canter et al., 2000; Levine, 2002; O'Leary, 2009; Rossmo, 2008). Las estrategias basadas en la distancia de probabilidad para determinar el punto de anclaje del criminal difieren entre sí en cuanto a la función matemática aplicada en torno a cada lugar del incidente. Por ello, elegir el tipo adecuado de función de

\footnotetext{
${ }^{10} \mathrm{http}: / /$ desktop.arcgis.com/es/desktop/

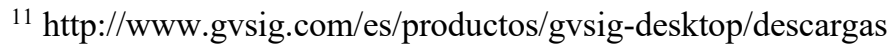

${ }^{12}$ Ned Levine (2015). CrimeStat: A Spatial Statistics Program for the Analysis of Crime Incident Locations (v 4.02). Ned Levine \& Associates, Houston, Texas, and the National Institute of Justice, Washington, D.C. August.

${ }^{13} \mathrm{http}: / / w w w . a h p . t o o l s /$ features.html
}

Revista Española de Investigación Criminológica

Artículo 13, Número 16 (2018)

https://doi.org/10.46381/reic.v16i0.197

www.criminologia.net

ISSN: 1696-9219 
decaimiento es uno de los mayores problemas en la creación de perfiles geográficos. Es necesario tener en cuenta que los diferentes algoritmos matemáticos empleados en la perfilación geográfica arrojan como resultado una superficie de probabilidad en la cual gestionar la actuación policial y no un punto concreto al cual dirigirse. Para nuestro estudio, el primer esquema se deriva de la fórmula de Rossmo (1995) expresada con un algoritmo de cuatro pasos:

1. Establece un área de estudio dividida en 40.000 celdas.

2. Por cada celda se calcula la distancia Manhattan a cada incidente. La distancia Manhattan es aquella en la que la distancia entre dos puntos es la suma de las diferencias absolutas de sus coordenadas.

3. Identifica si la celda se sitúa dentro de la zona de seguridad, una distancia igual a la mitad de la media de la distancia del vecino más cercano.

4. Si la celda está dentro o en el borde de la zona de seguridad entonces suma los valores usando la siguiente función (Figura 5).

El resultado es una superficie en la que los valores más altos en determinadas zonas indican la probabilidad de que un delincuente pueda vivir dentro de esa área, y la celda con una puntuación de probabilidad más alta determinará el punto de anclaje del delincuente.

Para este estudio seguimos la estrategia de Martin, Rossmo y Hammerschlag (2009) y utilizamos el 1\% de los valores máximos del geoperfil (400 celdas con los z-score más altos), lo que indica el área sugerida como de mayor probabilidad del domicilio del delincuente.

$$
p_{i, j}=k \sum_{n=1}^{c}\left[\frac{\phi}{\left(\left|X_{i}-x_{n}\right|+\left|Y_{j}-y_{n}\right|\right)^{f}}+\frac{(1-\phi)\left(B^{g-f}\right)}{\left(2 B-\left|X_{i}-x_{n}\right|-\left|Y_{j}-y_{n}\right|\right)^{g}}\right]
$$

Figura5: Fórmula CGT (Focalización Criminal Geográfica) de Rossmo (1995)

Dónde:

$$
\begin{aligned}
& \left|x_{i}-x_{n}\right|+\left|y_{j}-y_{n}\right|>B \supset \phi=1 \\
& \left|x_{i}-x_{n}\right|+\left|y_{j}-y_{n}\right| \leq B \supset \phi=0
\end{aligned}
$$

Revista Española de Investigación Criminológica

Artículo 13, Número 16 (2018)

https://doi.org/10.46381/reic.v16i0.197

www.criminologia.net

ISSN: 1696-9219 
Y:

Tabla 3.

Desglose de los parámetros de la fórmula CGT de Rossmo

Método PIRO

\begin{tabular}{|l|l|}
\hline Pij & Probabilidad de que el delincuente resida en el punto señalado \\
\hline $\mathrm{K}$ & Constante determinada experimentalmente \\
\hline $\mathrm{B}$ & $\begin{array}{l}\text { Radio de la zona de seguridad (mitas de la media del vecino más } \\
\text { cercano) }\end{array}$ \\
\hline $\mathrm{N}$ & Número total de incidentes \\
\hline $\mathrm{f}$ & Exponente determinado experimentalmente (1.2) \\
\hline $\mathrm{g}$ & Exponente determinado experimentalmente (1.2) \\
\hline $\mathrm{Xi}, \mathrm{yj}$ & Coordenadas del centroide de las celdas \\
\hline $\mathrm{X}_{\mathrm{m}}, \mathrm{y}_{\mathrm{m}}$ & Coordenadas de los incidentes (incendios en este caso) \\
\hline
\end{tabular}

Un problema que surge al diseñar un modelo de perfilado geográfico es decidir qué elementos incluir y cuáles deberían ser excluidos, a fin de garantizar que se están analizando los datos correctos y de la manera adecuada. Si se aplica el perfil geográfico a cualquier conjunto arbitrario de ubicaciones delictivas sin una buena comprensión de cómo los datos se ajustan al modelo, mayor será la distancia entre las conclusiones obtenidas y la explicación del fenómeno criminológico que se quiera analizar.

Para evitar aquellos incidentes que no se ajustan al patrón espacial normal observado en la serie, por representar un comportamiento anómalo del incendiario urbano, seleccionaremos aquellos incidentes que se producen para 2 desviación estándar elipsoidal (2X) y dando mayor peso a la serie de registros más cercanos en el tiempo, que representa 2 desviación estándar de las coordenadas X e Y del centro de la media. 
Por lo general, para 1 desviación estándar elipsoidal (1X) el 68\% de los incidentes se encuentran en el área de la elipse, mientras que 2 desviación estándar elipsoidal (2X) captura aproximadamente el 95\% de los incidentes (Figura 6).

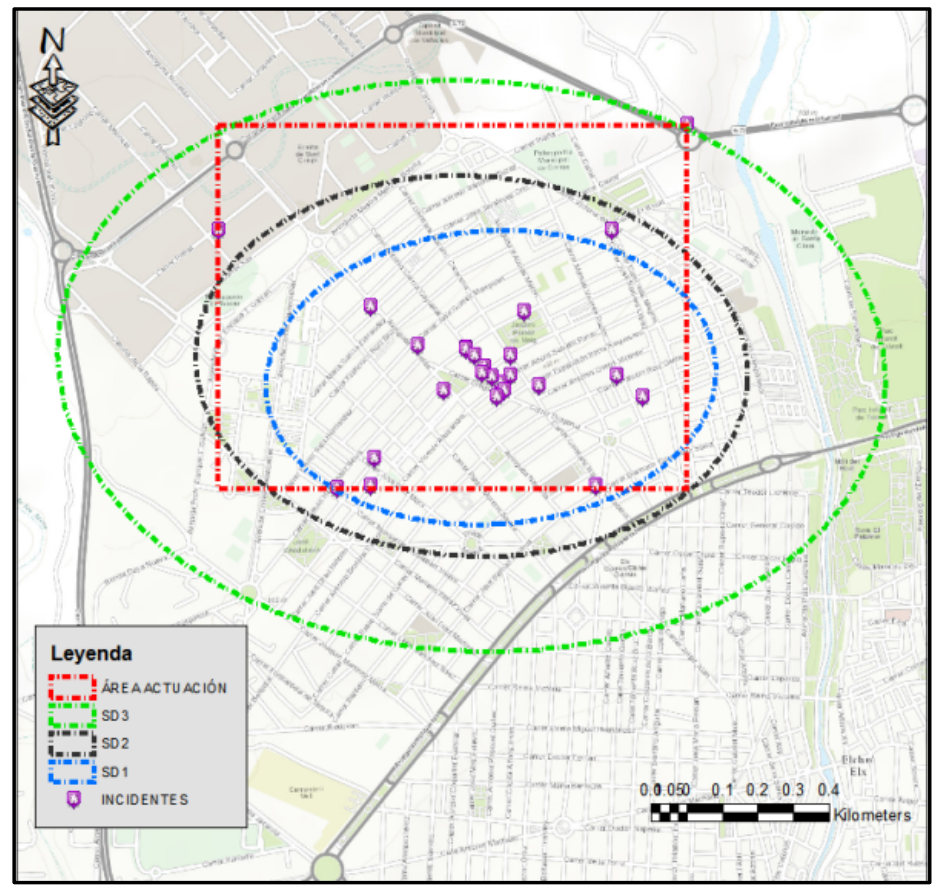

Figura 6: Zona de actuación y selección de casos. Desviación estándar elipsoidal

En la Figura 6, la circunferencia de color negro es la que corresponde a una elipse de 2 desviación estándar, por lo que los incendios ubicados fuera de la misma se eliminan del análisis.

En este contexto proponemos, formulamos y probamos una calibración en el valor $B$ de la ecuación de Rossmo (Figura 7). La calibración del modelo consiste en determinar los parámetros de la funciones de decaimiento de la distancia que mejor se ajuste a los datos. Existen múltiples métodos de calibración de parámetros, sin embargo, para el caso de los incendiarios, cualquiera que sea el escogido, éste debe considerar la unidad de tiempo y distancia entre los incidentes de la serie. El modelo propuesto se presenta a continuación.

$$
\boldsymbol{B}=\omega * \theta * \operatorname{Max}
$$

Figura 7: Parámetro B "buffer zone” de la fórmula CGT 
Donde Max es la distancia euclidiana entre el primer y último incidente de la serie dentro de 2 desviación estándar elipsoidal (2X), $\theta$ es el coeficiente normalizado con un valor de rango entre 0 y $1, y \omega$ es un coeficiente que se obtiene experimentalmente o heurísticamente con los valores de rango 0.4, 1.2 y 2.2, al aplicar un sistema de ajuste denominado análisis de cuadrante $Q \mathrm{~A}=\sqrt{2 * \mathrm{~A} / \mathrm{P}}$, donde $A$ es el área de actuación en metros cuadrados y $P$ es el $n^{\circ}$ de puntos dentro del área. El valor de $\omega$ depende entonces del valor del análisis de cuadrante. Así:

$$
\begin{aligned}
\text { Si QA es } \geq \text { Max entonces } \omega & =0.4 \\
\text { Si QA es } \leq \text { Max entonces } \omega & =1.2 \\
\text { Si QA es } \approx \text { Max entonces } \omega & =2.2
\end{aligned}
$$

El componente subjetivo del perfil geográfico se basa en la reconstrucción e interpretación del mapa cognitivo de un incendiario. Hay varios factores relacionados tanto con el incidente en sí como con el entorno (y la interacción entre estos dos) que se deben tener en cuenta en los parámetros de un modelo de perfilado geográfico (Rossmo\&Summers, 2015). En este sentido, aplicar un Proceso Analítico Jerárquico ${ }^{14}$, en adelante AHP, con factores correctores en una clasificación de incendiarios (serial, espontáneo, en masa o forestal), nos puede permitir conocer las preferencias espaciales en relación con la zona de seguridad alrededor de su domicilio. La emisión de juicios para el establecimiento de los pesos se ha realizado por comparaciones pareadas por un grupo de analistas y criminólogos, que ha permitido determinar los pesos del coeficiente normalizado $(\theta)$ entre los valores de rango 0 y $1[\mathrm{~B}=\omega * \theta * M a x]$ relacionados con el área de seguridad del delincuente. Para la obtención de dichos pesos se ha empleado el software Yaahp, a través del cual fueron cinco los criterios comparados (Figuras 8 y 9).

\footnotetext{
${ }^{14} \mathrm{La}$ metodología de toma de decisiones AHP, basada en la comparación por pares, es especialmente útil en las decisiones en las que sea necesario considerar numerosos y diferentes tipos de criterios y/o muchas posibles alternativas.
} 


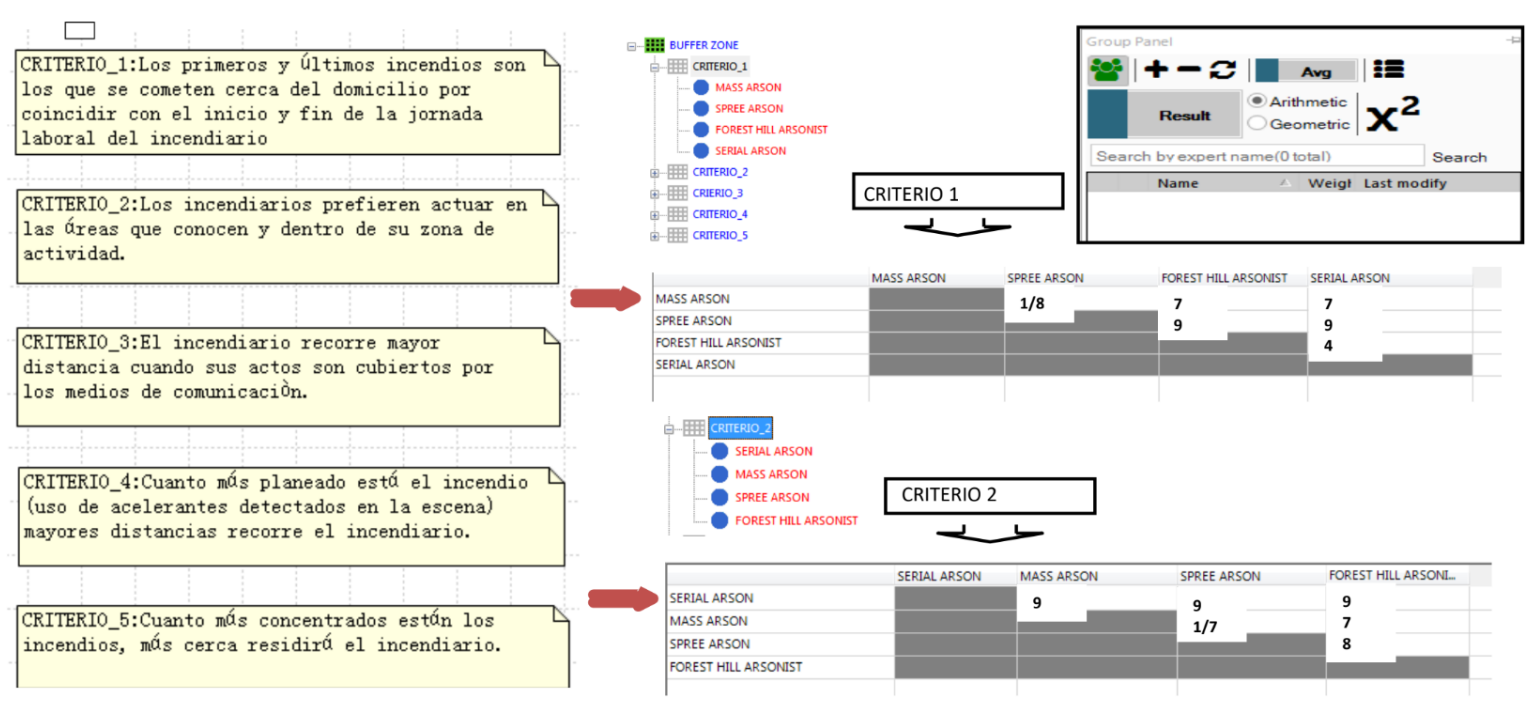

Figura 8: plantilla del software Yaahp para el cálculo del coeficiente normalizado $(\theta)$.

Criterios de comparación.
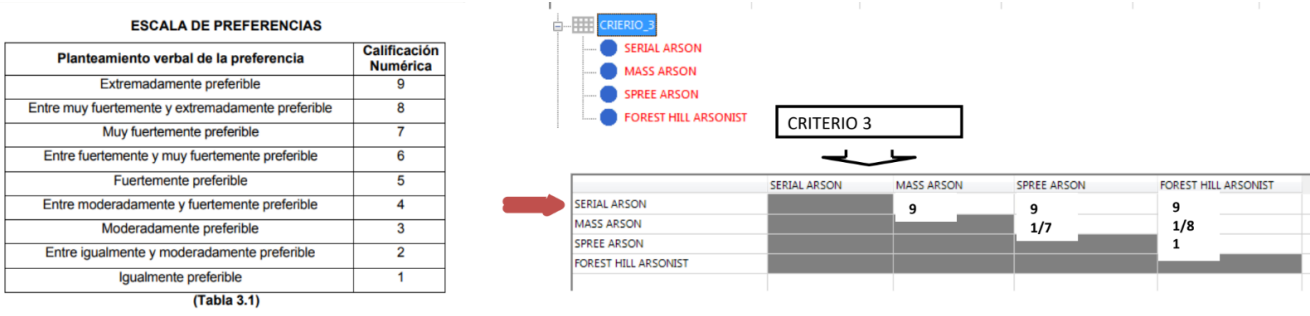

Figura 9: plantilla del software Yaahp para el cálculo del coeficiente normalizado $(\theta)$. Criterios de puntuación en la comparación por pares.

Para ilustrar el proceso de obtención del coeficiente normalizado $(\theta)$ para cada tipología de incendiario tomemos como ejemplo el criterio uno de la Figura 9 "los primeros $\mathrm{y}$ últimos incendios son los que se cometen cerca del domicilio por coincidir con el inicio y el fin de la jornada laboral del incendiario". Este criterio se compara por cada tipo de incendiario con el resto. Entonces, si se considera que el criterio1 se produce más para el incendiario en serie (tipología que se está comparando con el resto) que para el incendiario en masa, pondremos una puntuación entera (4, 6, o 9 por ejemplo), pero si se considera que es al revés pondremos una fracción (1/4, 1/6 o 1/9 por ejemplo). De esta forma, para cada criterio existen 16 comparaciones distintas (4 tipologías de incendiarios multiplicadas por 4

Revista Española de Investigación Criminológica

Artículo 13, Número 16 (2018)

https://doi.org/10.46381/reic.v16i0.197

www.criminologia.net

ISSN: 1696-9219 
tipologías de incendiarios). Este proceso se aplicó por dos analistas delictivos y una criminóloga. El software devuelve un resultado final (promedio de los pesos obtenidos por cada analista) una vez se han comparado los criterios con cada tipo de incendiario por pares (Tabla 4).

\section{Tabla 4.}

Resultado de la matriz de comparación por pares (media ponderada del grupo de decisión)

Nota: La asignación de los puntajes de importancia relativa se realizan comparando la importancia del primer indicador con respecto a los demás, de acuerdo con el método Saaty, 1980.

El estudio es realizado sobre tres escenarios distintos que representa diversos supuestos sobre el modelo teórico. Así, se obtiene una comprensión amplia del fenómeno del incendiario y se evalúa la robustez del modelo planteado y de su metodología de aplicación.

\begin{tabular}{|l|l|}
\hline Tipo de incendiario & Peso \\
\hline Incendiarios en serie & 0.4415 \\
\hline Incendiarios espontáneos & 0.3255 \\
\hline Incendiarios forestales & 0.1252 \\
\hline Incendiarios en masa & 0.1078 \\
\hline
\end{tabular}

\section{Resultados}

A continuación se muestran los resultados de perfilar geográficamente cada uno de los escenarios estudiados, según se trate del modelo PIRO o del modelo Rossmo. 


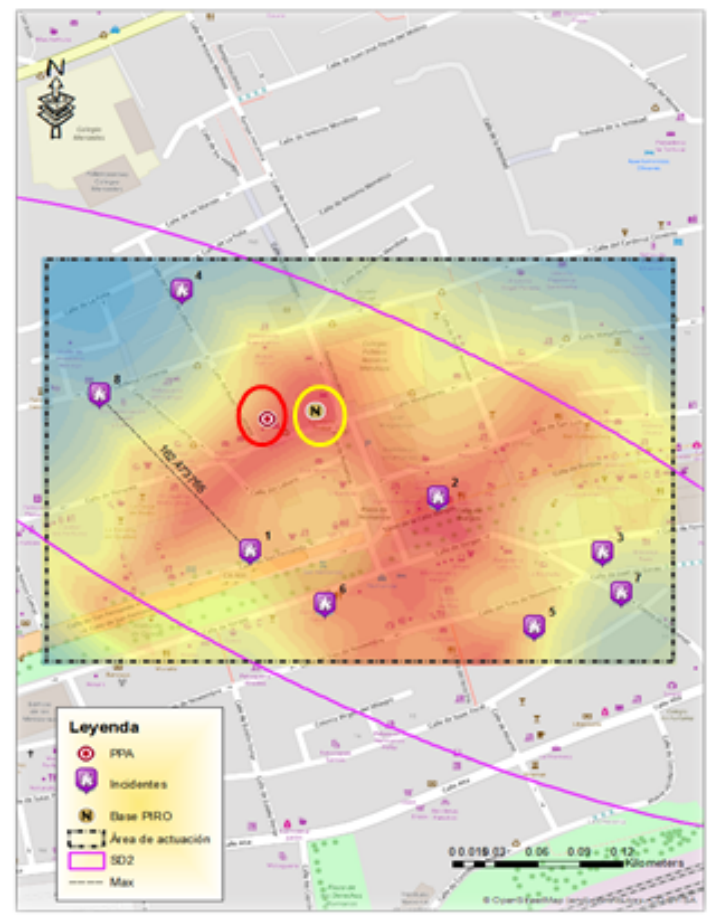

Figura 10: Modelo PIRO Santander

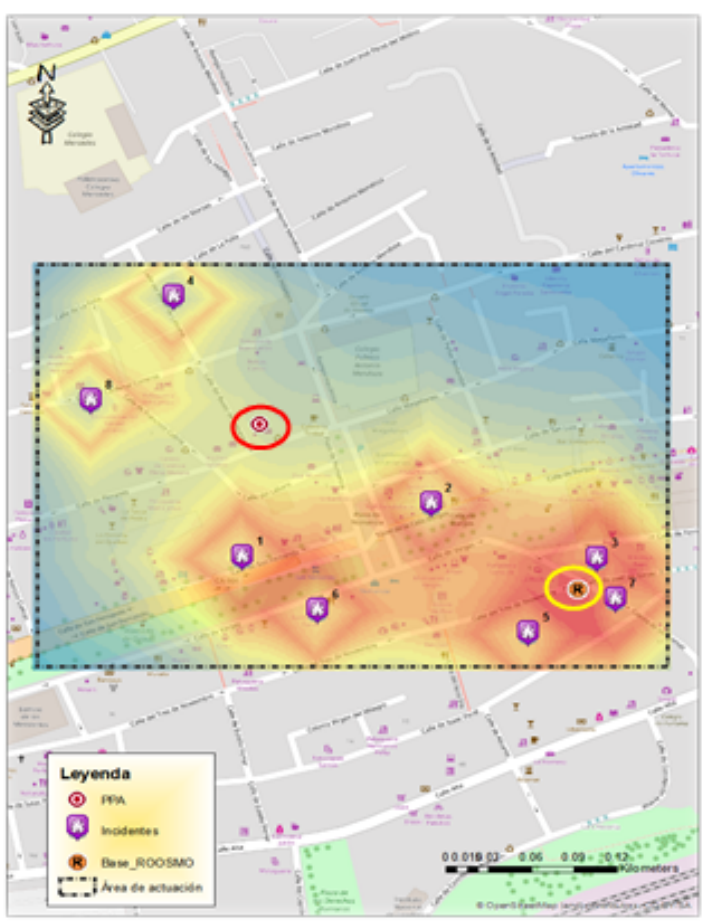

Figura 11: Modelo ROSSMO Santander

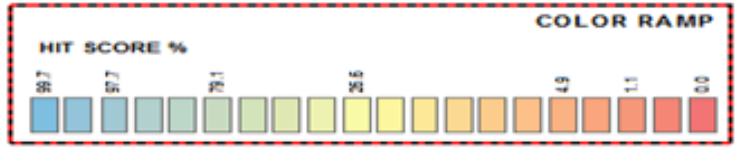

Nota:

- La circunferencia de color rojo rodea la localización del domicilio del incendiario, mientras que la circunferencia de color amarillo rodea el punto señalado por el geoperfil como posible residencia del incendiario.

- Los símbolos de color lila son las localizaciones de los distintos fuegos iniciados.

- Las siglas PPA (Punto de Anclaje Principal) se refieren al domicilio del incendiario.

- El símbolo "N", se refiere al punto que indica el geoperfil como más probable según modelo PIRO.

- El símbolo" $R$ " se refiere al punto que indica el geoperfil como más probable según modelo ROSSMO.

- La elipse de color lila indica la Elipse de 2 desviación estándar.

- El cuadrado de líneas discontinuas negras señala el área de actuación del incendiario.

- Max. se refiere a la distancia, en metros, entre el primer y último incendio. 


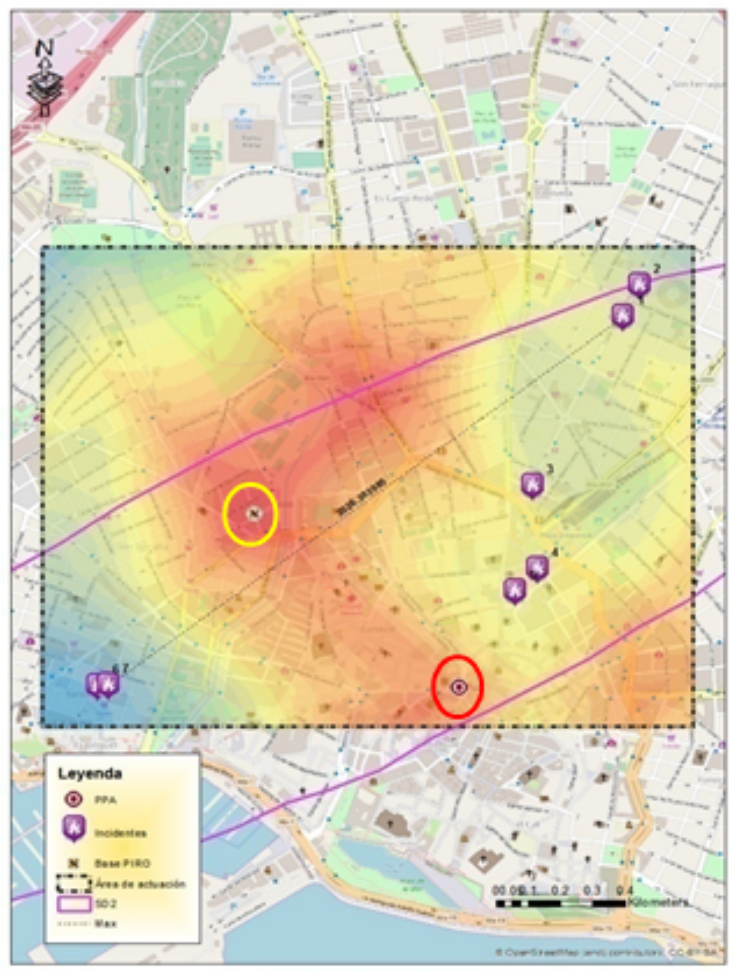

Figura 12: Modelo PIRO Palma Mallorca

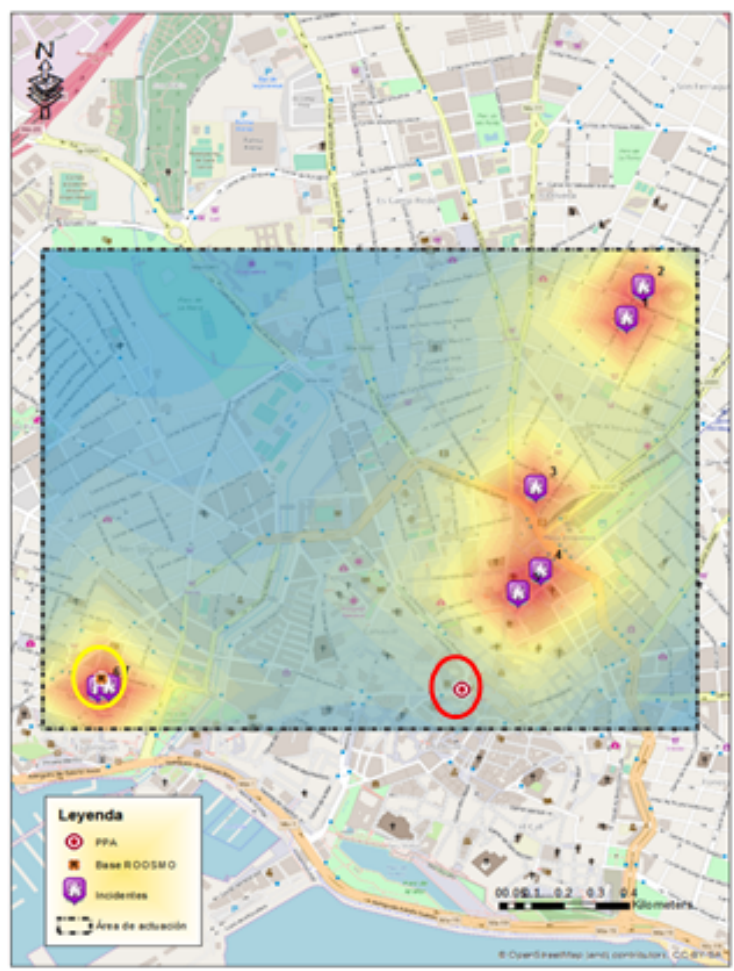

Figura 13: Modelo ROSSMO Palma Mallorca

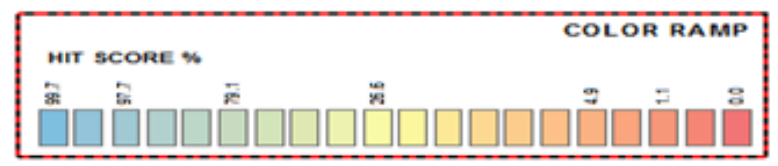

Nota:

- La circunferencia de color rojo rodea la localización del domicilio del incendiario, mientras que la circunferencia de color amarillo rodea el punto señalado por el geoperfil como posible residencia del incendiario.

- Los símbolos de color lila son las localizaciones de los distintos fuegos iniciados.

- Las siglas PPA (Punto de Anclaje Principal) se refieren al domicilio del incendiario.

- El símbolo “N”, se refiere al punto que indica el geoperfil como más probable.

- El símbolo"R" se refiere al punto que indica el geoperfil como más probable según modelo ROSSMO.

- La elipse de color lila indica la Elipse de 2 desviación estándar.

- El cuadrado de líneas discontinuas negras señala el área de actuación del incendiario.

- Max. se refiere a la distancia, en metros, entre el primer y último incendio.

Revista Española de Investigación Criminológica

Artículo 13, Número 16 (2018)

https://doi.org/10.46381/reic.v16i0.197

www.criminologia.net

ISSN: $1696-9219$ 


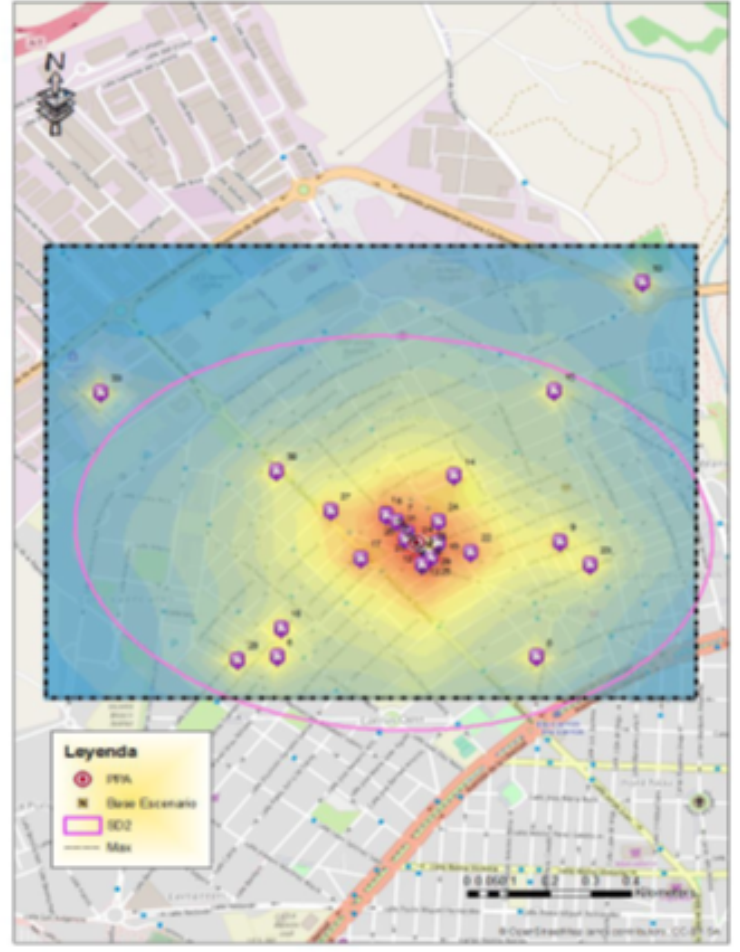

Figura 14: Modelo PIRO Elche

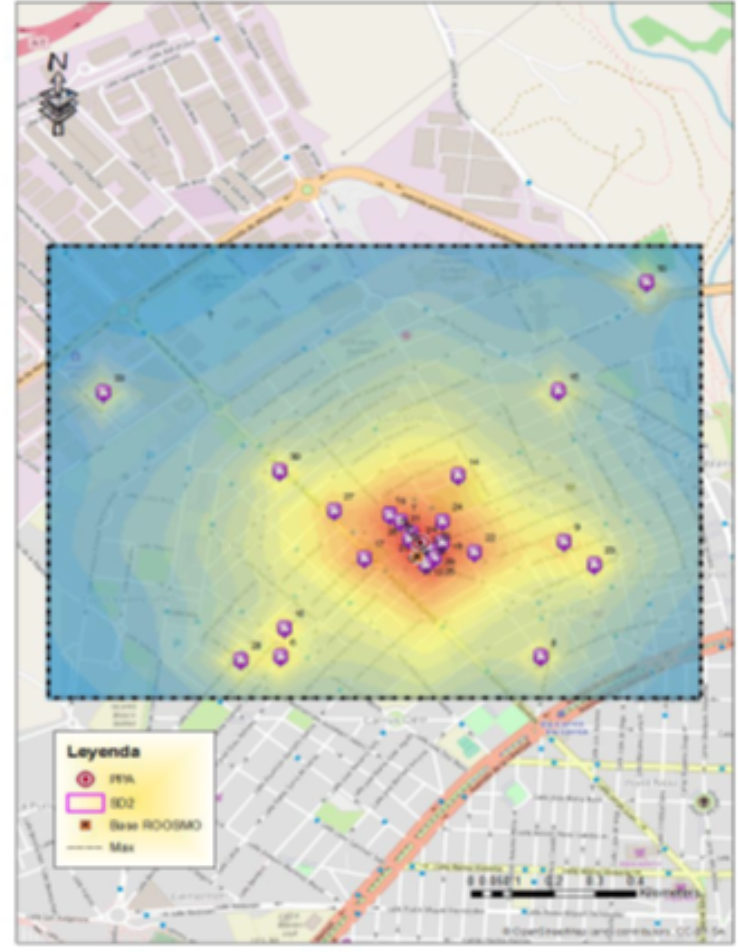

Figura 15: Modelo ROSSMO Elche

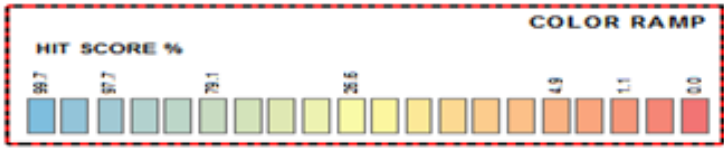

Nota:

- La circunferencia de color rojo rodea la localización del domicilio del incendiario, mientras que la circunferencia de color amarillo rodea el punto señalado por el geoperfil como posible residencia del incendiario.

- Los símbolos de color lila son las localizaciones de los distintos fuegos iniciados.

- Las siglas PPA (Punto de Anclaje Principal) se refieren al domicilio del incendiario.

- El símbolo " $N$ ", se refiere al punto que indica el geoperfil como más probable.

- El símbolo" $\boldsymbol{R}$ " se refiere al punto que indica el geoperfil como más probable según modelo ROSSMO.

- La elipse de color lila indica la Elipse de 2 desviación estándar.

- El cuadrado de líneas discontinuas negras señala el área de actuación del incendiario.

- Max. se refiere a la distancia, en metros, entre el primer y último incendio.

Revista Española de Investigación Criminológica

Artículo 13, Número 16 (2018)

https://doi.org/10.46381/reic.v16i0.197

www.criminologia.net

ISSN: 1696-9219 


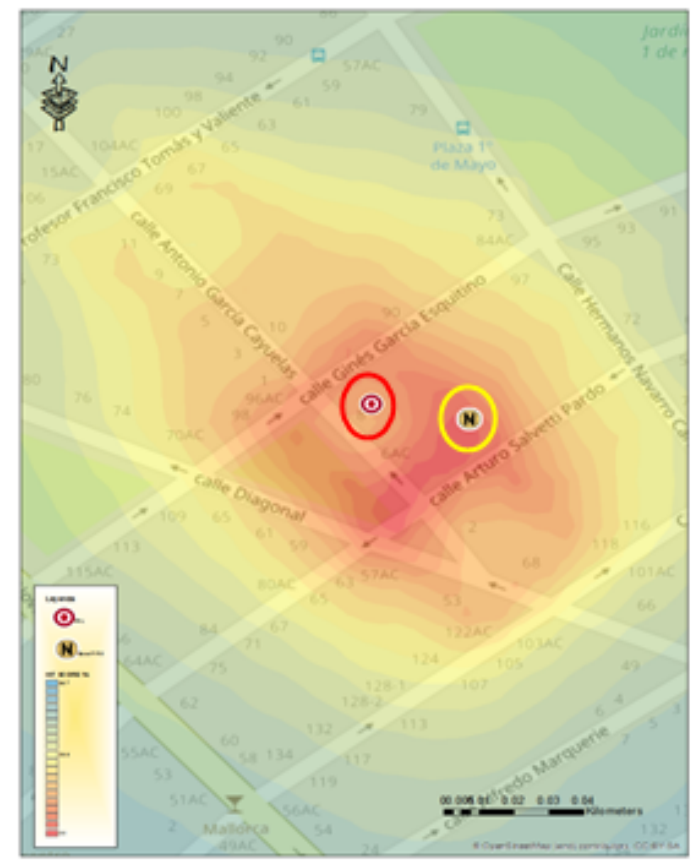

Figura 16: Detalle resultados PIRO Elche

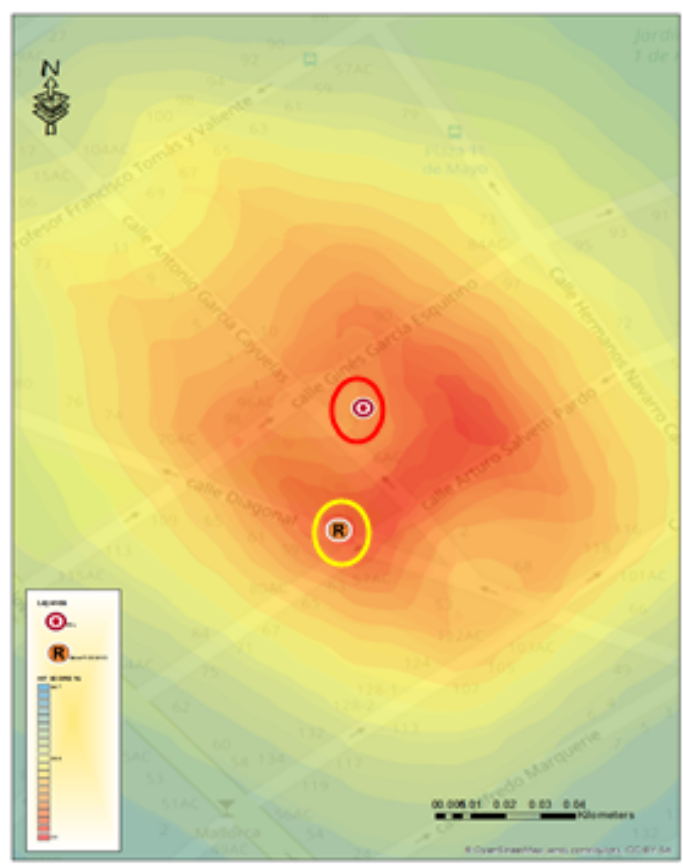

Figura 17: Detalle resultados ROSSMO Elche

Nota:

- La circunferencia de color rojo rodea la localización del domicilio del incendiario, mientras que la circunferencia de color amarillo rodea el punto señalado por el geoperfil como posible residencia del incendiario.

- Las siglas PPA (Punto de Anclaje Principal) se refieren al domicilio del incendiario.

- El símbolo " $N$ ", se refiere al punto que indica el geoperfil como más probable.

- El símbolo" $\boldsymbol{R}$ " se refiere al punto que indica el geoperfil como más probable según modelo ROSSMO

Los modelos de perfil evaluados para este estudio se compararon mediante el uso de técnicas que miden la capacidad de un perfil para localizar con precisión el punto de anclaje de los delincuentes en el conjunto de datos de la muestra del perfil. Existen múltiples técnicas para evaluar la eficacia de un modelo de perfil geográfico criminal (Rich\&Shively, 2004). Si bien algunas de estas medidas son controvertidas (ver Levine, 2005), se eligieron dos de las técnicas de evaluación más utilizadas para este estudio: distancia de error y coste de búsqueda. 
La distancia de error representa la distancia euclidiana medida entre el punto con mayor probabilidad que señala el geoperfil y la posición real de un punto de anclaje del delincuente (PPA). Las distancias de error menores equivalen a perfiles más precisos. En este caso el resultado del proceso nos da unos valores para los tres escenarios que pueden verse en la Tabla 8.

Tabla 8.

\begin{tabular}{|l|l|l|l|}
\hline \multirow{2}{*}{ ESCENARIO } & \multicolumn{2}{c|}{ DISTANCIA DE ERROR } & \multirow{2}{*}{ DIFERENCIA } \\
\cline { 2 - 3 } & ROSSMO & PIRO & \\
\hline Elche & 40 metros & 27 metros & -13 metros \\
\hline Palma de Mallorca & 1115 metros & 870 metros & -245 metros \\
\hline Santander & 257 metros & 35 metros & -225 metros \\
\hline
\end{tabular}

Comparación de las distancias de error resultantes de aplicar el modelo ROSSMO y el modelo PIRO

El resultado obtenido a partir de esta técnica, comparando las distancias entre el puntaje de más alta probabilidad y el domicilio del delincuente, resulta una frecuencia acumulada de 66\% entre el modelo PIRO y el de Rossmo. Como puede comprobarse, las distancias de error medidas para cada escenario indican un mejor rendimiento en el modelo PIRO.

Por su parte, el coste de búsqueda calcula la proporción del área de estudio que se debe buscar para identificar el punto de anclaje del delincuente. El coste de búsqueda es igual al número de celdas de la cuadrícula que deben ser buscadas antes de identificar el punto de anclaje real del delincuente. En consecuencia, menor número de celdas indican mayor precisión y menor porcentaje de coste de búsqueda en relación con el área de actuación.

Los resultados del coste de búsqueda se presentan comparando los valores porcentuales de las celdas ocupadas en relación al área de actuación. 
Puede observarse cómo los costes de búsqueda resultantes de aplicar el modelo PIRO para el caso de Santander son mucho menores que los generados de aplicar el modelo Rossmo. Dichos costes de búsqueda pueden verse representados en el siguiente mapa (Figura 18).

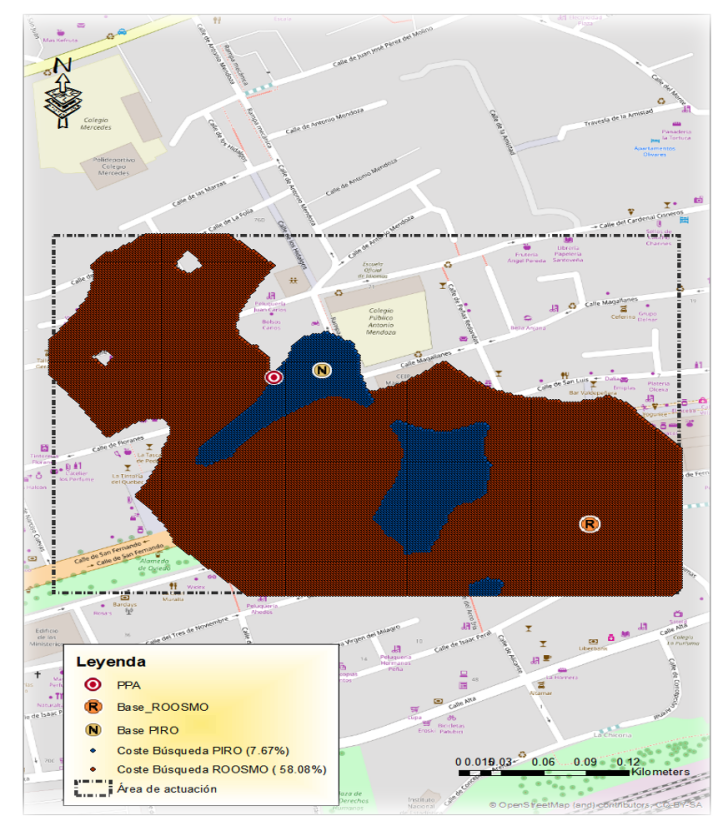

Figura 18: Comparación de los costes de búsqueda entre el modelo PIRO y ROSSMO para el escenario Santander.

\section{Discusión}

El cálculo del área de seguridad con el método PIRO para el estudio de los incendiarios al realizar un perfilado geográfico puede considerarse una alternativa al modelo de Rossmo (1995), pues tanto la distancia de error como los costes de búsqueda son mucho más reducidos en comparación con los resultados obtenidos de aplicar la fórmula CGT sin realizar el ajuste propuesto en el parámetro B de la función. La incorporación de las tres nuevas variables determina y ofrece más estabilidad en la búsqueda del domicilio de los incendiarios urbanos. Así, hemos comprobado que el modelo PIRO ofrece un rendimiento superior al de la ecuación Rossmo. 
No obstante lo anterior hay que recordar que los tres casos analizados ocurrieron en España, con unas características culturales y geográficas que influyen tanto en la distribución espacio-temporal del delito como en las distancias que recorren los delincuentes desde su domicilio hasta el lugar del delito. Y esto es así porque el espacio local está perturbado por ciertas características geográficas, y ésta es una realidad que el perfil geográfico no asume. Un ejemplo son las diferencias en los robos entre las ciudades de Rotterdam y Ámsterdam. Rotterdam fue bombardeada al comienzo de la Segunda Guerra Mundial. Al término de ésta, la ciudad fue re-construida, existiendo ahora calles muy anchas. Sin embargo, Ámsterdam seguía teniendo sus tradicionales calles estrechas. Pues bien, el cambio en las calles marcó también un patrón distinto en los robos. Así, en Ámsterdam la mayoría de los robos ocurrían cerca de las líneas de transporte público de la zona, mientras que en Rotterdam presentaba más robos usando vehículos. Por tanto, la distancia recorrida por el criminal desde su residencia hasta el lugar del crimen es mucho mayor que la que recorre el criminal en Ámsterdam, lo que afecta a ese principio de decaimiento con la distancia, influenciado por las características geográficas (Van der Kemp\& Van der Koppen, 2008).

La mayor precisión a la hora de señalar el área donde es más probable que resida el incendiario urbano mejora la capacidad de las Fuerzas de Seguridad para identificar al responsable de los incendios y evitar, por tanto, la continuación de dichos incidentes en la vía pública. En otras palabras, los esfuerzos investigativos se reducen y es posible concentrar los recursos disponibles en las áreas señaladas por el geoperfil que son, como consecuencia de aplicar el modelo PIRO, más exactas. Pero la mejora de los resultados derivados del ajuste matemático no se limita a los incendiarios urbanos, sino que puede extenderse a otros comportamientos y tipologías delictivas. Dicho de otro modo, es posible aplicar la metodología presentada en este estudio a otros fenómenos delictivos, de manera que el perfil geográfico arroje mejores resultados a la hora de identificar el domicilio de un agresor sexual, un ladrón o un asesino, por ejemplo.

No obstante, son diversas las cuestiones que quedan pendientes y que en un futuro deberán ser abordadas. En primer lugar destaca el tamaño de la muestra en el estudio planteado. La dificultad para la recolección completa de los datos necesarios para el estudio

Revista Española de Investigación Criminológica

Artículo 13, Número 16 (2018)

https://doi.org/10.46381/reic.v16i0.197

www.criminologia.net

ISSN: 1696-9219 
supone un obstáculo que podría solventarse con la creación de una base de datos de incendiarios en la vía pública, a partir de la cual puedan extraerse variables suficientes para replicar estudios como éste y extraer más conclusiones al respecto. En segundo lugar, es necesario seguir trabajando en el ajuste del componente subjetivo del perfil geográfico e incorporar más analistas delictivos en la ponderación del coeficiente $\theta$, relacionado con la zona de seguridad del delincuente, lo que permitiría una visión más extensa, multidisciplinar y una mayor ponderación en los pesos. Por último, en el contexto en que se desarrolla este estudio es más realista usar algoritmos de cálculo de costes de recorrido en los que se tienen en cuenta la existencia de la red viaria. En un futuro pueden considerarse nuevos ajustes para determinar la tipología de medición de la distancia. 


\section{Referencias}

Álvarez, F.J. (2004). Diccionario básico de criminalística $2^{a}$. ed. Bogotá, Colombia: Ecoe Ediciones.

American PsychiatricAssociation., Kupfer, D. J., Regier, D. A., Arango López, C., AyusoMateos, J. L., Vieta Pascual, E., \&BagneyLifante, A. (2014). DSM-5: Manual diagnóstico y estadístico de los trastornos mentales (5a ed.). Madrid [etc.]: Editorial Médica Panamericana.

Aniceto, J.J. (2008). ¿Incendiario o pirómano? Claves para la determinación de la piromanía como causa de los incendios forestales (tesis doctoral). Universidad de Cádiz. Cádiz, España

Aniceto, J.J. (2017). Informe sobre determinadas cuestiones relacionadas con el incendiario urbano en la vía pública. Junta de Andalucía.

Bartol, C. \&Bartol, A. (2012). Criminal \&BehavioralProfiling. California, EstadosUnidos: SAGE publications.

Bogomolov, A. et al. (2014). Once Upon a Crime: Towards Crime Prediction from Demographics and Mobile Data. Proceedings of the 16th International Conference on Multimodal Interaction. ICMI'14. 427-434. doi: http://dx.doi.org/10.1145/2663204.2663254

Brantingham, P., Brantingham, P. (1981). Mobility, Notoriety, and Crime: A Study in the Crime Patterns of Urban Nodal Points. Journal of Environmental Systems, 11(1), 8999.

Canter, D., Coffey, T., Huntley, M., \&Missen, C. (2000). Predicting serial killers? home base using a decision support system. Journal of Quantitative Criminology, 16(4), 457478.

Canter, D. \& Youngs, D. (2008). Geographic profiling of criminals. En D. Canter (Ed.), Principles of geographical offender profiling (pp. 197-220). Aldershot, ReinoUnido: Ashgate.

Craglia, M., Haining, R. \&Wiles, P., (2000). A Comparative Evaluation of Approaches to Urban Crime Pattern Analysis. Urban Stud. 37(4), 711-729.

Curman, A. (2004). Spatial-statistical analysis of arson activity in the greater Vancouver region of British Columbia (tesis de maestría). Simon Fraser University, Vancouver, Columbia.

Davis, J.A., Lauber, K.M. (1999). Criminal behavioral assessments of arsonists, pyromaniacs, and multiple firesetters. Journal of Contemporary Criminal Justice, 15(3), 273-290.

Douglas et al (2006). Crime Clasification Manual. A standard systmen for investigating and classifying violent crimes. San Francisco, California: Jossey-Bass.

Revista Española de Investigación Criminológica

Artículo 13, Número 16 (2018)

https://doi.org/10.46381/reic.v16i0.197

www.criminologia.net

ISSN: 1696-9219 
Edwards, M.J. (2004). Psychological profiling: analyzing spatial patterns of convicted serial arsonists (tesis doctoral) University of Canterbury. Canterbury, Reino Unido.

Estudio sobre detenidos en materia de incendios. Perfil del incendiario. Análisis de la Comunidad Autónoma de Galicia. (8 de septiembre de 2010). El Mundo, p.29.

Felson, M. \& Clarke, R. V. (1998). La ocasión hace al ladrón. Teoría práctica para la prevención del delito. Claves del Gobierno Local (6). 193-234.

Fernández, M. (15 de Noviembre de 2014). La quema de contenedores le cuesta a Zaragoza más de 174.000 euros este año. Heraldo. Recuperado de: https://www.heraldo.es/noticias/aragon/zaragoza_provincia/zaragoza/2014/11/14/el _vandalismo_cuesta_zaragoza_mas_174_000_euros_que_ano_321992_301.html

Fritzon, K. (2001). An examination of the relationship between distance travelled and motivational aspects of fire-sitting behaviour. Journal of Environmental Psychology, 21(1).45-60.

Hewitt, A. \& Beauregard, E. (2017). Offender mobility during the crime: Investigating the variability of crime event contexts and associates outcomes in stranger sexual assaults. Sexual assaults: a journal of research and treatment, 24(4), 313-341. doi: https://doi.org/10.1177/1079063215594377

Hurtado, T. \& Bruno, G. (2009). Proceso De Análisis Jerárquico (Ahp). Revista Digital UNMSM. Recuperado de: http://sisbib.unmsm.edu.pe/bibvirtualdata/Tesis/Basic/toskano_hg/cap3.PDF

Jiménez, V.M.(2013). Costal \& Marine. California, Estados Unidos. Gulf of California Marine Program. Recuperado de: http://gulfprogram.ucsd.edu/blog/coastal-andmarine/importancia-de-los-sistemas-de-informacion-geografica-sig-en-laconservacion/.

Kielasinska, E. (2011). The geography of urban arson in Toronto. School of Geography and Earth Science (tesis doctoral). McMaster University, Hamilton, Ontario.

Kocsis, R. N. \& Irwin, H. (1997). An analysis of spatial patterns in serial rape, arson, and burglary: The utility of the circle theory of environmental range for psychological profiling. Psychiatry, Psychology and Law, (4). 195-206. doi: 10.1080/13218719709524910.

Kocsis, R. \& Cooksey, R. (2002). Criminal psychological profiling of serial arson crimes. International Journal of OffenderTherapy and ComparativeCriminology,46(6). 631656.

La policía atribuye entre 4 y 9 incendios a un pirómano que actúa en portales de Santander. (21 de Marzo de 2011). Europapress. Recuperado de: http://www.europapress.es/cantabria/noticia-policia-atribuye-incendios-piromanoactua-portales-santander-20110321155556.html 
Levine, N. (2002). CrimeStat II: A spatial statistics program for the analysis of crime incident locations. Washington, DC: National Institute of Justice

Levine, N. (2015). CrimeStat: A Spatial Statistics Program for the Analysis of Crime Incident Locations (v 4.02). Ned Levine \& Associates, Houston, Texas, and the National Institute of Justice, Washington, D.C. August.

Lundrigam, S. \&Czarnomski, S. (2006). Spatial characteristics of sexual assault in New Zeland. The Australian and New Zeland Journal of Criminology, 39(2), 218-231.

Martin, R. A., Rossmo, D. K., \& Hammerschlag, N. (2009). Hunting patterns and geographic profiling of white shark predation. Journal of Zoology, 279(2), 111-118. doi: https://doi.org/10.1111/j.1469-7998.2009.00586.x

Ned Levine \& associates (2005). The Evaluation of Geographic Profiling Software: Response to Kim Rossmo's Critique of the NIJ Methodology. Recuperado de: http://nedlevine.com/

O'Leary, M. (2009). A new mathematical approach to Geographic Profiling. Department of Mathematics. Towson University. 3-86.

Rossmo, D. K. (1995): Geographic Profiling: Target patterns of serial murderes(tesis doctoral). Simon Fraser University, Vancouver, Canadá.

Rossmo, D. K. (2000). Geographic Profiling. Miami, Florida: CRC Press.

Rossmo, D.K., Rombouts, S. (2008). Geographic profiling. En R. Wortley \& M. Tonsley. (Ed.), Environmental Criminology and Crime Analysis (pp. 273-312). New York, New York: Routledge.

Rossmo, D. K. y Summers, L. (2015) El perfil geográfico en la investigación criminal. International e-Journal of Criminal Science 3(9). 1-24.

Saaty, T. L., \& Wiley, J. (2009). Capítulo Iii Proceso De Análisis Jerárquico (Ahp). Revista Digital UMMSM.

Snook, B., Zito, M., Bennell, C. \& Taylor, P.J. (2005). On the complexity and accuracy of geographic profiling strategies, Journal of Quantitative Criminology 21(1).1-26.

Tamura, M. \& Suzuki, M. (1997) Criminal profiling research on serial arson: Examinations of circle hypothesis estimating offender's residential area. Reports of the NationalResearch Institute of Police Science, Research on Prevention of Crime and Delinquency, 38: 13-25.

US Department of Justice (2004). A methodology for evaluating Geographic Profiling Software. Recuperado de: https:/www.ncjrs.gov/pdffiles1/nij/grants/208993.pdf

Van Daele, S. (2010). Mobility and distance decay at the aggregated and individual level. In M. Cools, B. De Ruyver, M. Easton, L. Pauwels, P. Ponsaers, G. VandeWalle, T. Vander Beken, F. Vander Laenen, G. Vermeulen \& G. Vynckier (Ed.), Safety,

Revista Española de Investigación Criminológica

Artículo 13, Número 16 (2018)

https://doi.org/10.46381/reic.v16i0.197

www.criminologia.net

ISSN: 1696-9219 
societal problems and citizens' perceptions: new empirical data, theories and analyses (pp.41-59). Antwerp, Bélgica: Maklu.

Van der Kemp, J. \& Van Koppen, P. (2008). Fine-Tune Geographical Profiling. In N. K. Richard. (Ed.) Criminal Profiling (pp. 347-364). Totowa, New Jersey: Humana Press Inc.

Warren J, Reboussin, R., Hazelwood, R. R., Cummings, A., Gibbs, N. \&Trumbetta, S. (1998). Crime Scene and distance correlates of serial rape. Journal of Quantitative Criminology, 14(1), 35-59.

White, C. (1932). The relations of felonies to environmental factors in Indianapolis. Social Forces, 10(4), 498-509.

Wiles, P., Costello, A. (2000). The "road to nowhere": the evidence for traveling criminals. Home Office Research Study (207).1-2.

Zouh, J., Lian, L. \& Chen, L.. (2012). Geographic Profiling Based on Multi-point Centrography with K-means Clustering. International Journal of Mathematical, Computational, Physical, Electrical and Computer Engineering (6) 1. 114-117.

\section{Agradecimientos}

Nos gustaría agradecer a José Joaquín Aniceto su apoyo a esta investigación, al compartir con nosotros su experiencia en el campo de investigación y al elaborar un informe exclusivo para nosotros. A las criminólogas Patricia Saldaña y Patricia Rodríguez-Manzaneque por su labor en el proceso complejo de comparaciones por pares, siendo parte fundamental en la obtención de los pesos para cada incendiario. A José Ignacio Trojaola, Jefe del Servicio de Bomberos de Santander, por su disposición a ayudarnos con la identificación de los puntos de incendios del caso en concreto. A los periodistas Lorenzo Marina y Mariña Rivas por indicarnos algunos pasos a seguir en el proceso de obtención de datos.

Daniel Salafranca es Doctorando en Criminología, con Máster Universitario en Sociología y Antropología de las Políticas Públicas, Licenciado en Ciencias Políticas y de la Administración, Diplomado en Gestión y Administración Pública. Profesor-colaborador en el Centro Crímina (Universidad Miguel Hernández) en el Máster Oficial en análisis y prevención del crimen.

(iD https://orcid.org/0000-0003-3442-2001

\section{Revista Española de Investigación Criminológica}

Artículo 13, Número 16 (2018)

https://doi.org/10.46381/reic.v16i0.197

www.criminologia.net

ISSN: 1696-9219 
Diego J. Maldonado es Doctorando en Ciencias Sociales y Jurídicas, con Máster Universitario en Análisis y Prevención del Crimen, Graduado en Criminología y Seguridad, e Investigador pre-doctoral en la Universidad de Cádiz. Recibió el Premio Eulen Excelente, el Premio Extraordinario Fin de Grado y el Premio al Mejor Trabajo Fin de Máster.

(iD https://orcid.org/0000-0002-5283-0634

Revista Española de Investigación Criminológica

Artículo 13, Número 16 (2018)

https://doi.org/10.46381/reic.v16i0.197

www.criminologia.net

ISSN: 1696-9219 